\title{
A produção de sujeitos inclusivos na contemporaneidade: um olhar para a história (recente) das práticas escolares ${ }^{1}$
}

Eliana da Costa Pereira de Menezes*

\section{Resumo}

A discussão aqui proposta busca conhecer práticas escolares postas em operação para a produção de sujeitos úteis a uma sociedade que se pretende inclusiva. Produzido na esteira das discussóes pós-estruturalistas e, ancorado metodologicamente em duas ferramentas advindas das teorizaçóes foucaultianas - governamentalidade e subjetivação, o texto analisa registros de práticas escolares (de diferentes décadas) arquivados em um acervo de uma escola pública que possui mais de um século de existência. Ao trabalhar nos materiais foi possível perceber recorrências discursivas implicadas na produção de relaçóes de governamento de si e dos outros - a defesa gradativamente crescente da necessidade de desenvolvimento da autonomia escolar e dos sujeitos escolares; o estímulo à centralização das práticas não apenas nos conteúdos a serem aprendidos, mas também nas competências e habilidades a serem desenvolvidas; a necessidade de autogestão para a conquista de melhores condiçóes de vida, entre outras questôes - para a fabricação de determinadas subjetividades, cujos efeitos entende-se que sejam de mobilização para a inclusão nos dias de hoje. Tais questôes foram lidas como deslocamentos que anunciam a emergência da governamentalidade neoliberal, a partir da qual o significado do termo inclusão ganha novos contornos, podendo ser lido como um princípio de Estado mobilizado para a organização da vida da população na contemporaneidade.

Palavras-chave: Inclusão; Subjetivação; Governamento.

\footnotetext{
* Professora doutora da Universidade Federal de Santa Maria, Santa Maria, Rio Grande do Sul, Brasil.
} 


\section{The production of inclusive subjects in contemporaneity: a look at the (recent) history of school practices}

\section{Abstract}

This discussion aims to understand school practices operating for the production of useful subjects to a society intended to be inclusive. Based on post-structuralist discussions and methodologically grounded on two Foucauldian tools - governmentality and subjectivation - this paper analyzes records of school practices (from different decades) from the files of a public school which is older than one century. Working on such material has enabled us to perceive discursive recurrences involved in the production of relations of government of the self and the others - the gradually increasing defense of the need for the development of school autonomy and school subjects; the encouragement of the centralization of practices not only in the contents to be learned, but also in the competences and skills to be developed; the need of self-management for the accomplishment of better life conditions, among other things - for the production of certain subjectivities whose effects are understood as mobilizing for inclusion nowadays. These issues have been regarded as displacements announcing the emergence of neoliberal governmentality, in which the meaning of the word 'inclusion' has acquired new contours and can be read as a State principle mobilized for population life organization in contemporaneity.

Keywords: Inclusion; Subjectivation; Government.

\section{A produção de sujeitos inclusivos na contemporaneidade: um olhar para a história (recente) das práticas escolares}

Nas últimas décadas do século XX, na medida em que discursos políticos, acadêmicos, midiáticos, etc. passaram a produzir a inclusão como uma verdade inquestionavelmente boa para todos, tornou-se natural defender a necessidade de sua materialização nos diferentes espaços sociais, entre eles a escola. Partindo de um olhar desconfiado com relação a naturalização dos discursos inclusivos, e considerando que na Contemporaneidade os espaços existentes para discutir ou relativizar a obrigatoriedade da inclusão escolar são mínimos, produzi minha pesquisa de Doutorado ${ }^{2}$ a partir da qual procurei compreender como a escola opera a produção de subjetividades na (para a) sociedade inclusiva contemporânea. Da investigaçáo empreendida na construção dessa investigação, foi possível compreender que o desenvolvimento da capacidade empreendedora e da capacidade de acompanhar a evolução da sociedade, desenvolvendo habilidades e competências de forma autônoma, são hoje condições importantes para a vida contemporânea. $\mathrm{O}$ alcance de tais condiçóes implica que os sujeitos desenvolvam capacidade de autocondução, de acordo com os princípios de nossa época, a partir do necessário e permanente investimento em si (e nos outros). E é esse investimento em si como condição de desenvolvimento pessoal que mobiliza os sujeitos permanentemente que vejo caracterizando um estado de inclusão a ser alme- 
jado por todos nós (o que justifica a necessidade de investimento também nos outros) para que nos mantenhamos participantes das redes de consumo na lógica neoliberal.

A partir da constatação de que, em diferentes esferas, a inclusão passa a ser produzida como obrigatória, foi possível compreender que ela acabara se constituindo como imperativa na vida dos sujeitos, de todos eles. Nesse momento, o significado desse termo ganha para mim novos contornos. Passo a olhá-lo como um princípio de Estado que operacionaliza diferentes estratégias para a produçáo de sujeitos que se autogestem a partir de princípios neoliberais. Tais princípios impóem que os sujeitos desenvolvam condiçôes de participação, de empreendedorismo, de concorrência e de consumo, entre outros. Ninguém pode ficar de fora da lógica do mercado; aqueles, que porventura não conseguem conquistar tais condiçôes poderão constituir-se como uma ameaça ao equilíbrio econômico do país, o que significa, em um contexto neoliberal, o equilíbrio do país e das relaçôes internacionais que esse país estabelece de uma forma geral. Assim, as possibilidades de manutenção de todos na condição de normalidade, objetivo das ações inclusivas, nesse contexto neoliberal, passam a ser lidas pela ótica da seguridade.

Faz-se preciso incluir para a produção da normalização, para a inserção e permanência de todos nas redes de mercado, para a manutenção da seguridade da população. Nessa lógica, o agenciamento do Estado com a escola aparece como uma possibilidade (entre outras) privilegiada para a produção de sujeitos subjetivados para esse fim, afinal, que outra instituição melhor se encarrega da produção dos sujeitos dentro de uma determinada racionalidade? Percebendo entáo a ênfase que as açóes inclusivas ganham nos discursos educacionais e que me anuncia que na Contemporaneidade se faz preciso que todos, sem exceçôes, sejam incluídos, senti-me instigada a produzir a investigaçáo ora citada, cujo presente texto constitui o capítulo no qual busco conhecer práticas escolares postas em operação para a produção de sujeitos úteis a uma sociedade que se pretende inclusiva.

Para tanto, na esteira das discussôes pós-estruturalistas e, ancorada metodologicamente em duas ferramentas advindas das teorizaçóes foucaultianas - governamentalidade e subjetivaçáo, analiso registros de práticas escolares (de diferentes décadas) arquivados em um acervo de uma escola pública que possui mais de um século de existência. Ao trabalhar nos materiais foi possível perceber recorrências discursivas implicadas na produção de relaçóes de governamento de si e dos outros na lógica inclusiva, conforme as problematizaçóes que seguem.

\section{A produção de sujeitos úteis a uma sociedade que se pretende inclusiva}

Opondo-se à ideia de uma essência constitutiva do sujeito, a compreensão de sujeito — sujeitado "a alguém pelo controle e dependência, e preso à sua própria identidade por uma consciência ou autoconhecimento" (FOUCAULT, 1995, p. 235) - na perspectiva foucaultiana possibilitou-me compreender que nos tornamos o que somos por diferentes tipos de saberes, por relaçóes de poder e por relaçóes que estabelecemos conosco mesmos, na busca pela verdade que nos constitui. A esse respeito, Avelino (2010) pontua que 
O poder da verdade [...] contra o qual a anarqueologia se opóe, opera, sobretudo, sob a forma de subjetividade: é no momento em que somos chamados a nos constituir como Sujeito que aceitamos o império dos discursos científicos e não-científicos que têm por função revelar aquilo o que verdadeiramente somos. (AVELINO, 2010, p. 25).

Assumir esse olhar anarqueológico para compreender o sujeito, segundo Foucault (2010) significa assumir uma "atitude filosófica" de suspeita diante do poder da verdade que nos subjetiva. Trata-se, ao fim e ao cabo, de não mais nos perguntarmos sobre os vínculos que nos ligam voluntariamente a verdade para identificarmos o que pensamos sobre o poder, mas sim de nos perguntarmos, considerando nossa vontade de desfazermos a ligação que nos liga ao poder, o que acontece com o sujeito de conhecimento e da verdade? (Foucault, 2010). O que se busca, nessa lógica, não é a negação ou a aceitaçáo daquilo que tomamos como verdadeiro, mas sim a compreensão do poder da verdade e de seus efeitos na produção das subjetividades. Portanto, no contexto deste trabalho, procurei olhar para discursos e práticas (escolares) assumidos como verdadeiros, e que possibilitaram a emergência de tipos específicos de subjetividades, adaptáveis ao modo de vida das sociedades contemporâneas, que eu nomeio como inclusivas.

Tais subjetividades são significadas por mim, entre outras características, como aquelas que, mobilizadas pelo acesso (sem restriçôes) e pela igualdade de oportunidades que lhes são ofertados, se sentem estimuladas (sujeitando-se) ao autoinvestimento. Esse autoinvestimento pode resultar em acúmulo de capital humano (pelo desenvolvimento de habilidades e competências, pela construção de saberes e novas aprendizagens...), o que, por sua vez, poderá resultar em uma (sensação de) maior autonomia pelos sujeitos em suas decisóes e escolhas, além de maiores condiçóes de participação nas redes de consumo. Ao experimentar a (sensação de) liberdade para fazer suas escolhas em um meio que lhe apresenta múltiplas e variadas ofertas, esse sujeito usufrui do acesso que lhe é ofertado, alimentando o ciclo da oferta e do consumo da lógica neoliberal, o que (re)compensaria os investimentos do Estado em sua educação.

Essa capacidade de inclusão da sociedade contemporânea passa, então, pela necessidade de desenvolvimento de condiçôes de investimento em si. Investir em si para desenvolver e acumular seu capital, aquilo que lhe dará condiçóes de concorrência, aquilo que lhe possibilitará inventar possibilidades ainda não pensadas, resolver problemas, inovar, empreender. Hoje tais características constituem a gramática escolar, uma gramática constituída por discursos que buscam a produção de sujeitos capazes de atuação nessa sociedade que não cessa de se transformar.

Nessa esteira, é possível perceber que as aprendizagens consideradas importantes não dizem mais respeito especificamente aos saberes e à construção do conhecimento. Estes são importantes, mas aparecem articulados a todo o momento à necessidade de desenvolvimento de habilidades e competências. Estas podem ser avaliadas pelas relaçóes que os alunos estabelecem com a escola e que se mostram como efeitos das relaçóes que o sujeito é capaz de estabelecer consigo próprio. 
Essa necessidade de desenvolvimento de determinadas competências e habilidades, que hoje aparece de forma explícita nos documentos da escola, foi observada por mim na análise empreendida em documentos da década de 60 do século passado. Nessa análise, foi possível perceber recorrências discursivas que tomo como condição de possibilidade para as práticas que subjetivam os alunos para mobilizarem-se pela inclusão, desenvolvidas no contexto escolar atual. Assim, o olhar analítico direcionado para pareceres de professores sobre seus alunos anuncia-me que tais características podem ser consideradas como aquelas que antecedem a produção das subjetividades que hoje nomeio como inclusivas.

L. M. B.: Planejou atividades muito ricas para os seus alunos, demonstrou habilidade para manejar a classe, confecçáo de material adequado. Demonstrou muita iniciativa e responsabilidade.

C. L. P.: Acatou sempre as sugestôes para um melhor trabalho. De início teve um problema de disciplina, mas procurou sanar e venceu logo. Muito responsável e dedicada, não houve muita criatividade no seu trabalho, aproveitou mais as sugestôes de suas orientadoras.

M. S.: Com dificuldade de planejamento e sem confiança em si. No inicio trabalhou muito apoiada, logo foi adquirindo maior segurança, visto ter dominado plenamente a turma. Muito responsável, solícita, acatando as sugestöes para melhorar. Tem muita força de vontade apesar de não ter muita iniciativa.

S. N.: Tem muito poder de criatividade e iniciativa. Sua turma era passiva e ela conseguiu que eles participassem. Na culminância das Unidades, a participação dos alunos era falar sobre o que aprendeu nas aulas.

V. R.: Ótima estagiária. Iniciou muito bem o seu trabalho, esforçando-se cada vez mais. Tem muito entusiasmo e iniciativa. Alguns trabalhos são bastante originais. A classe é muito ativa e o rendimento é bom. O planejamento é ótimo, bem variado, grande, porque os alunos exigem muitas atividades.

(Pareceres de orientação de estágio. Relatórios 1969, 1974, 1983)

Criatividade, iniciativa, motivação, entusiasmo, dinamismo e autoconfiança aparecem aqui como características que precisam ser desenvolvidas pelos alunos. Alunos esses que se preparam para tornarem-se professores ${ }^{3}$ e que por isso se encontram na condição de aluno/estagiário, sendo ao mesmo tempo subjetivados para desenvolver tais características e também para produzi-las em seus alunos. Dupla ação de subjetivação, intensificação de força no investimento em capital humano.

A Teoria do Capital Humano constitui uma forma de análise econômica empreendida pelos economistas da Escola de Chicago entre as décadas de 50 e 60 do século passado, a partir da qual a noção de trabalho ganha novos significados, sendo reintroduzida nessas análises. A Teoria em questáo defende a tese de que as destrezas, habilidades e aptidóes dos sujeitos adquirem valor de mercado e passam a constituir-se em capital. Aqui falo então de um capital não-material, entendido a partir 
do desenvolvimento de componentes que, adquirindo valor de mercado, passam a constituir cada indivíduo, independentemente da classe social em que ele esteja inserido, como o seu próprio capital. Cabe a esse indivíduo investir nele mesmo, cada vez mais e permanentemente, para que acumule cada vez mais capital e para que tenha, cada vez mais, condiçóes de concorrência com outros indivíduos que estão também ocupados com seu próprio autoinvestimento.

"Esse capital humano é composto de quê? Pois bem, ele é composto [...] de elementos que são elementos inatos e de outros que são elementos adquiridos" e é sobre esses últimos, conforme Foucault, que se colocam as análises e as problematizaçôes empreendidas pelos neoliberais (FOUCAULT, 2008, p. 312). Na esteira dessa governamentalidade que tem como raiz de inteligibilidade a economia e as relaçôes de mercado, a escola aparece como lugar privilegiado, uma vez que nela múltiplas práticas de investimento em si e nos outros podem ser postas em funcionamento, acarretando "não só o aumento da produtividade do indivíduo-trabalhador, mas a maximização crescente de seus rendimentos ao longo da vida" (GADELHA, 2009, p. 177).

Dessas análises, pode-se perceber que a necessidade de investimento em capital humano passa obrigatoriamente pela necessidade de investimento em educação. Aqui, ressalta Foucault, os neoliberais não estão fazendo referência apenas à necessidade de investimento na instruçáo escolar, na produçáo de saberes, na aprendizagem de conteúdos e habilidades profissionais e também não estão se referindo somente às práticas educacionais postas em operação nos espaços escolares. Eles falam também do tempo destinado às relaçóes entre pais e filhos, do tempo que os sujeitos dedicam aos cuidados com sua saúde, ao lazer, aos esportes. São atividades através das quais "o capital humano poderá primeiro ser melhorado, segundo ser conservado e utilizado pelo maior tempo possível" (FOUCAULT, 2008, p. 316).

A produção desse capital não passa exclusivamente pela escola, mas sabe-se que depende também (em grande parte) dela. É a escola que, agenciada com essas outras instituiçóes e práticas, acabará subjetivando seus alunos, desde pequenos, à necessidade de investimento em si para uma autogestâo dentro dos princípios neoliberais.

Segundo Foucault (2008), ao se falar em neoliberalismo americano, fala-se em um indivíduo concebido como uma empresa, que é gestado como se funcionasse como uma empresa e que se autogesta como um empresário de si, "sendo ele próprio seu capital, sendo para si mesmo seu produtor, sendo para si mesmo a fonte de [sua] renda" (FOUCAULT, 2008, p. 311). Nessa lógica, o acúmulo de capital pressupóe a operação de práticas que busquem subjetivar os indivíduos para o "cuidado de si", para que se conheçam, para que saibam no que precisam investir mais e melhor, para que não deixem de se mobilizar permanentemente em busca de seu aperfeiçoamento. 
S. R.: Pouco hábil no manejo da classe, insegura e deficiente na elaboração do plano de aula, a princípio não obteve o dominio da turma. Graças ao seu esforço, foi lentamente superando essas deficiências. Já no final do estágio, apresentava bom nivel de trabalho.

A. M.: Muito organizada, planejou atividades muito relacionadas, ricas. Devido ao seu tipo de temperamento - em alguns momentos da execução, deixou de ter a firmeza necessária-gerando certa indisciplina na classe. Graças aos recursos apontados por esta orientaçấo conseguiu relativa melhora no trabalho.

L. B: Estagiária muito responsável, demonstrou grande interesse pelo seu trabalho. A princípio demonstrou ligeira falta de auto-controle e espontaneidade, falta essa compensada imediatamente após o aconselhamento da orientadora. Desenvolveu muito bem o seu trabalho.

M. C.: Turma turbulenta, nivel intelectual baixissimo, pois não houve uma seleçäo para a organização dessa classe. Mesmo assim, a estagiária embora apresentasse desde o início segurança, entusiasmo, era muito responsável, viu-se diante de diversos problemas, mas devido ao seu espirito dinâmico solucionou as dificuldades, terminou o seu estágio com ótimo rendimento.

R. P.: Destacou-se pela sua grande força de vontade em vencer, mostrando muito esforço e persistência em progredir, apesar de não demonstrar facilidade para conseguir um bom manejo, uma boa visáo de conjunto. Porém, por iniciativa própria resolveu separar seus alunos segundo suas dificuldades. No final do estágio mostrou um grande progresso.

(Pareceres de orientação de estágio. Relatórios 1969, 1974, 1983)

Segurança, persistência, esforço, vontade de progredir. Entendo que tais características podem ser lidas na esteira do investimento em si para compensação de dificuldades, de obstáculos. Cada aluna, apesar das dificuldades apontadas, mostra-se disposta a buscar seu autoaperfeiçoamento, o que, na lógica neoliberal, é condição indispensável para a manutenção dos sujeitos nas relações de mercado.

É preciso que o sujeito não esmoreça, é preciso que ele se mantenha ativo, que não desista diante das dificuldades e dos obstáculos encontrados; é preciso que ele acredite nas suas capacidades para que encontre motivos para investir em si. Tal postura, acrescida das capacidades antes destacadas (criatividade, iniciativa, motivaçáo, entusiasmo, dinamismo, autoconfiança), entre outras, produz um sujeito com condiçôes de inclusão nas tramas neoliberais. Aquele que é capaz de empreender porque acredita que tem condiçóes para isso; que, tendo medo de arriscar, o faz porque entende que é preciso manter-se em atividade; que cria novas soluçôes para problemas que também são novos.

Conforme Gadelha (2010), a noção de empreendedorismo pode ser compreendida de diferentes formas, pelo menos desde 1970. No agenciamento com a Teoria do Capital Humano, aquela que o autor destaca como sendo a que mais se relaciona é a que remete a uma 
[...] "visão de mundo", a um modo de "ser" e "estar" no mundo, em suma, a um estilo de vida a ser adotado e cultivado, e que é modulado pelas capacidades de sonhar, de transformar ideias em realidade, de identificar oportunidades/investimentos, de competir, de definir seu próprio destino, de inovar, mas também pela ousadia em correr riscos, pela eficácia, pela eficiência, pela flexibilidade, pelo "ser pró-ativo" etc. (GADELHA, 2010, p. 21).

Entendo que a concorrência constitui-se como uma característica central desse modo de estar no mundo operado pela lógica neoliberal. Uso Gadelha (2010, p. 22) para reforçar meu argumento quando ele a indica como "um dos traços mais decisivos do empreendedorismo" na Contemporaneidade. Assim, esse outro com quem eu concorro é cada vez mais produzido como aquele que me ameaça, como aquele que, não cessando de investir em si, acabará me ultrapassando, ocupando os lugares por mim desejados, satisfazendo desejos que podem ser iguais aos meus. Esse sujeito é produzido como um potencial risco à minha vida, e é em nome da prevenção desse risco que eu preciso também desenvolver permanentemente açóes de autoinvestimento.

Nessa lógica, ao perceber em todos, e em qualquer um, um concorrente em potencial, difícil se torna confiar em alguém, se relacionar, estabelecer vínculos duradouros. Somos cada dia mais sujeitos a uma sociedade de indivíduos, segundo Castel (2009). Para esse autor, esse processo de individuação crescente pelo menos nos últimos 30 anos pode ser lido especialmente a partir das mudanças que a sociedade contemporânea tem imprimido ao mundo do trabalho. Ele destaca que temos assistido a uma individualização das tarefas, o que exige do trabalhador dos nossos dias "mobilidade, adaptabilidade e responsabilidade a assumir". Nesse contexto, diz ele, no mundo do trabalho, temos exigido dos trabalhadores "um envolvimento pessoal de cada um, pondo em concorrência, ao mesmo tempo, todos contra todos" (CASTEL, 2009, p. 114).

A esse respeito, o autor diz que tal individualização pode constituir-se como uma característica produtiva para a vida em sociedade daqueles que conquistam boas condiçóes de investimento em si, desenvolvem competências e se mostram bons competidores. No entanto, o "não-dito" desse discurso, para usar uma expressão sua, faz referência àqueles sujeitos que, não desenvolvendo condiçóes de investimento em si, não conquistam espaço na lógica da concorrência - "não necessariamente porque seriam mais burros que os outros, mas porque lhes faltam suportes e recursos para o enfrentamento dessas novas exigências" (CASTEL, 2009, p. 115); assim, acabam ficando em situação de desvantagem com relação aos demais. Entendo que o problema não é a existência de desigualdade nas relaçóes de concorrência - estas são imprescindíveis; o problema está no fato de, por algum motivo e em algum momento, os meus concorrentes cessarem de existir.

Considerando, então, que o ciclo de oferta e de consumo da lógica neoliberal se torna possível exatamente pela existência dessas relaçóes de concorrência, entendo que se faz preciso cada vez mais açóes de investimento nesses outros para que os sujei- 
tos, todos eles, se constituam como potenciais competidores em situaçóes equiparadas (pelo menos, minimamente equiparadas). Nesse sentido, me parece lógico que as subjetividades produzidas para esse modo de vida (que eu nomeio como inclusivas), além de preocuparem-se consigo, devam também ocupar-se com os outros para que todos tenham condições de inclusão nessa sociedade.

Trata-se de subjetividades inclusivas que se mobilizam permanentemente, a partir de características do modo de vida contemporâneo, para que estejam e permaneçam nas redes de consumo (o que, na sociedade de seguridade, na governamentalidade neoliberal, significa estar em situação de normalidade e, portanto, estar em condição de inclusão), como já foi destacado. Elas são também subjetividades inclusivas porque estabelecem relaçóes com o outro, mobilizando-o igualmente para o desenvolvimento de características necessárias para a lógica da concorrência, incluindo-se nas redes de consumo e nelas movimentando-se para permanecer.

O que fica claro aqui é que, nessa sociedade de indivíduos, alimentada pela lógica da competição, que por sua vez estimula açóes de autoinvestimento, a preocupação com o outro, como destaca Gadelha (2010), é calculada a partir da relação custo-benefício, isso porque, ao fim e ao cabo, preciso que o meu investimento no outro resulte em meu benefício próprio. Assim, na esfera da ocupação com o outro, o estímulo às açóes inclusivas justifica-se pela aposta na possibilidade de que gradualmente esse sujeito cuja conduçáo é assumida pelos outros possa passar a assumir-se, desenvolvendo condiçóes de investimento em si. Com isso, passará a constituir-se como mais uma subjetividade que busca por si só incluir-se na sociedade contemporânea e que, por isso, também se constitui como sujeito capaz de responsabilizar-se por alguém, caso seja preciso.

Considerando a necessidade da subjetivação de todos com relação à responsabilidade que temos com aqueles que precisam (temporária e/ou permanentemente), as práticas escolares mostram-se atravessadas por uma série de "estratégias que se constituem em 'tecnologias do eu', que vão incidir sobre os sujeitos escolares de modo a subjetivá-los" (LOPES et al, 2010, p. 27) a ocuparem-se com os outros.

Os exemplos de trabalhos construídos pelos alunos na "Hora da Moral" e publicados no jornal da escola são lidos por mim como práticas que operam a relação do sujeito consigo, pela mediação da escola.

Vendo um aleijado dentro de um carro, num um dia em que o sol estava muito forte e o pobre com muita fome, fiquei compadecida. Arranjei, então, um prato de comida, $e$ dei-lhe também um chapéu para abrigar-lhe do sol.

Certo dia vi um velhinho mendigo que não podia passar em uma valeta, dei-lhe a mão e o pobre velhinho me agradeceu e continuou seu caminho muito contente.

Passando por uma igreja, vi uma velhinha muito pobre e fiquei comovida. Pedi emprestado 400 e dei-os àquela velhinha. Ela agradeceu, pareceu-me então que eu estava subindo até alcançar o céu. 
("Minha melhor ação", trabalhos da Hora da Moral. Jornal "A Instrução", Dezembro/1941).

Entendo que tais práticas cumprem duas funçôes importantes nas açôes de subjetivação. O próprio sujeito que avalia suas ações para que possa verbalizá-las opera sobre si açóes de governamento que o levarão, supostamente, à repetiçẫo daquelas açôes moralmente avaliadas como positivas, bem como à renúncia daquelas consideradas negativas. Quanto aos demais sujeitos, aqueles que não foram solicitados a se "confessarem", ao tomarem conhecimento das ações de seus colegas, poderiam exercer sobre si técnicas de autoexame que resultariam também em uma autocondução para fins morais, afinal, era provável que em um futuro próximo lhes fosse solicitado contar sua "melhor ação". Como vimos, é o exame de consciência que vai possibilitar ao sujeito um conhecimento de si. É esse exame que possibilita que identifiquemos se existe algum pensamento que pode nos tornar passíveis de erros, o que nos desviaria do caminho considerado correto.

Conforme Larrosa (2002, p. 45), as práticas de educação moral "têm a ver com elementos do domínio moral, com disposiçôes ou atitudes, com normas e com valores, mas de uma forma muito particular". Segundo o autor, náo se trata aqui de ensinar normas e valores que precisam ser seguidos por imposição, mas sim de fazer com que, ao falar, o aluno reflita sobre os seus comportamentos, comunicando-os. Nesse sentido, a criança produz seu texto no mesmo momento em que o texto produz a criança (Larrosa, 2002). Caberá a cada aluno realizar o exame de sua consciência a partir dos princípios e valores morais vigentes na sociedade. Caberá ao aluno constituir-se como fiscal permanente de si mesmo e avaliar se está se preocupando com o outro suficientemente.

Assistir voluntariamente os alunos "carentes", doar alimentos e dinheiro, proteger do frio, ajudar a atravessar a rua, entre outras, são posturas que aparecem aqui como assumidas pelos alunos como necessárias à sua formação, em especial porque elas partem de princípios morais instituídos socialmente. Tais práticas constituem-se, na minha leitura, como indispensáveis para a produção de sujeitos que na Contemporaneidade assumam como sua a responsabilidade de condução daqueles que não apresentam condições de investimento em si. O que quero mostrar é que as ações de caridade que têm nas práticas cristãs sua matriz e que subjetivavam os indivíduos pela possibilidade de conquista da salvação foram pouco a pouco sendo assumidas pelo Estado e inseridas nas práticas escolares.

Portanto, a caridade, a benevolência, a tolerância, a necessidade de ajuda ao outro para que eu me sinta melhor não são verdades produzidas na Contemporaneidade, e nem mesmo emergem com a invenção da escola. Isso me possibilita visualizar a escola articulando normas forjadas por formas de vida de épocas distintas, e que não são contraditórias, o que faz com ela seja moderna e contemporânea, numa relação de complementariedade, para que os sujeitos produzidos vivam na confluência de seus tempos. 
As ações de caridade, ao ganharem novas roupagens e significados, passando a ser produzidas discursivamente na trama dos direitos humanos, nos subjetivam para nos ocuparmos com os outros (supostamente) por uma questáo de princípios morais. Tais açôes têm nos constituído como sujeitos, de tal forma que se tornam imperativas na Contemporaneidade. Em termos morais, não há negociaçóes com relaçâo à necessidade que assumimos (especialmente conosco mesmos) de atender da forma como for preciso aquele que é produzido como necessitado de nossa atenção.

Nesse sentido, Gadelha (2010) indica que, na Contemporaneidade, as subjetividades têm sido trabalhadas para que desenvolvam

\section{[...] um mínimo de sensibilidade ao social, à pobreza, à violência, à discriminação, às condiçôes do meio ambiente, ao "politicamente correto", ao desenvolvimento sustentável, etc. Mas toda essa sensi- bilidade, a rigor, não é mais que um adorno numa lógica que pre- tende produzir, por um lado, indivíduos submissos e despolitizados e, por outro, indivíduos instados a competir permanentemente uns com os outros, a arcarem sozinhos com os insucessos e sucessos de seus investimentos e de suas apostas. (GADELHA, 2010, p. 28).}

Esses discursos que imprimem nos sujeitos a necessidade de olhar para o outro, para que esse outro se torne seu potencial concorrente, em alguns momentos, parecem-me um tanto perversos, principalmente quando açôes de competição têm como efeitos demarcaçóes entre normalidade e anormalidade, que incidem sobre os sujeitos, subjetivando-os com relação a um maior ou menor investimento em si. Ainda assim, sejam esses discursos compreendidos (e julgados) como perversos ou não, eles atravessam as práticas escolares (além de outras práticas) e constituem as relaçôes que estabelecemos atualmente, das quais poderemos escapar em alguns momentos, mas não em todos.

Assim, penso ser possível visualizar na problematização que constitui o presente texto a análise de acontecimentos que possibilitaram a emergência e o fortalecimento da governamentalidade neoliberal que, agenciando-se à maquinaria escolar, coloca em operação práticas para a produção de subjetividades que buscam sua inclusão na sociedade contemporânea e que assim contribuem para a prevenção dos riscos e para a manutenção da seguridade de todos.

Os discursos inclusivos que ecoam dentro das escolas, produzidos a partir de práticas de governamento que têm como centro e fonte de governo o mercado, podem ser lidos como estratégias de subjetivação dos indivíduos, cujos efeitos nós apenas começamos a conhecer. Sujeitos cada vez mais individualizados, que se encontram politicamente enfraquecidos, cuja capacidade de resistência aparenta ter perdido sua potência. E é exatamente porque essa é apenas uma impressão, porque nossa capacidade de resistência permanece presente, porque as relaçốes de poder são sempre atravessadas pela possibilidade de escolhermos outras formas de condução (na busca de outras verdades), que este estudo se justifica. 


\section{Referências}

AVELINO, N. Foucault e a anarqueologia dos saberes. In.: FOUCAULT, M. Do governo dos vivos. Curso no Collége de France, 1979-1980 (excertos). São Paulo: Centro de Cultura Social; Rio de Janeiro: Achiamé, 2010.

CASTEL, R. As metamorfoses da questáo social. Uma crônica do salário. 8a ediçâo. Petrópolis: Vozes, 2009.

FOUCAULT, M. Do governo dos vivos. Curso no Collége de France, 1979-1980 (excertos). Săo Paulo: Centro de Cultura Social; Rio de Janeiro: Achiamé, 2010.

FOUCAULT, M. Nascimento da Biopolítica. São Paulo: Martins Fontes, 2008.

FOUCAULT, M. O Sujeito e o Poder. In: DREYFUS, Hubert L; RABINOW, P. Michel Foucault. Uma Trajetória Filosófica: para além do estruturalismo e da hermenêutica. Rio de Janeiro: Forense Universitária, 1995. p. 231-249.

GADELHA, S. S. Biopolítica, governamentalidade e educaçáo. Introdução e conexôes, a partir de Michel Foucault. Belo Horizonte: Autêntica, 2009.

LARROSA, J. Tecnologias do Eu e Educação. In.: SILVA, T. T. O sujeito da educaçáo. Estudos Foucaultianos. 5 a ed. Petrópolis: Vozes, 2002.

LOPES, M. C. et. al. Inclusão e Biopolítica. Cadernos IHU Ideias. São Leopoldo: UNISINOS, 2010.

MENEZES, E. C. P. A Maquinaria escolar na produçáo de subjetividades para uma sociedade inclusiva. (Doutorado em Educação) - Programa de Pós- Graduação em Educação, Universidade do Vale do Rio dos Sinos. 2011.

\section{Notas}

${ }^{1}$ Alguns fragmentos presentes neste texto foram apresentadas no VII Congresso Nacional de Educaçáo, realizado no período de 22 a 24 de Agosto de 2011 na UNISINOS/São Leopoldo/RS.

${ }^{2}$ Pesquisa desenvolvida durante o Curso de Doutorado em Educaçáo na UNISINOS, no período de 2008 a 2011, sob orientação da professor Maura Corcini Lopes, financiada pela CAPES e, a partir da qual recortei o fragment que constitui o presente texto.

\section{Correspondência}

Eliana da Costa Pereira de Menezes - Universidade Federal de Santa Maria, Departamento de Educação Especial. Av. Roraima, no 1000, Cidade Universitária, Camobi. CEP: 97105-900 - Santa Maria, Rio Grande do Sul - Brasil.

E-mail: elianacpm@hotmail.com

Recebido em 06 de maio de 2015

Aprovado em 27 de agosto de 2015 